\title{
On convergence and error analysis of the parametric iteration method
}

\author{
S. A. Saeed Alavi ${ }^{1}$, Aghileh Heydari ${ }^{1}$, Farhad Khellat ${ }^{2}$ \\ ${ }^{I}$ Department of Mathematics, Payame Noor University, Tehran, I.R of Iran \\ ${ }^{2}$ Department of Mathematic, Faculty of Mathematical sciences, Shahid Beheshti University, Evin-Tehran, Iran \\ *Corresponding author E-mail: alavi601@yahoo.com
}

Copyright $\odot 2015$ S. A. Saeed Alavi et al. This is an open access article distributed under the Creative Commons Attribution License, which permits unrestricted use, distribution, and reproduction in any medium, provided the original work is properly cited.

\begin{abstract}
Parametric iteration method falls under the category of the analytic approximate methods for solving various kinds of nonlinear differential equations. Its convergence only for some special problems has been proved. However in this paper, an analysis of error is presented, then due to it, the convergence of method for general problems is proved. To assess the performance of the claimed error bound and also the convergence of the method, numerical experiments are presented performed in MATLAB 2012b.
\end{abstract}

Keywords: He's Variational Iteration Method; Parametric Iteration Method; Convergence; Error Bound.

\section{Introduction}

Parametric iteration method (PIM) is an analytic approximate method for solving linear and nonlinear problems proposed in [1]. At beginning it was proposed for solving nonlinear fractional differential equations by modifying He's variational iteration method (VIM) [2]. The PIM enjoys some augmented factors which made it more completed than the VIM. In fact by adjusting these factors one can establish more accurate approximations in comparison with the VIM.

During recent decade, many researchers have been worked on the VIM for solving various kinds of problems which mentioning them is out of the scope of this paper. Besides, some authors have been centered on the convergence of the VIM for some specific problems, like for multi-order fractional DE's [3], multi-delay DE's [4], ODE's [5], systems of ODE's [6] and etc. Herein, the work of Odibat [7] is more interesting and different because of its generality. In fact, he concluded the convergence of the VIM by introducing a semi-contraction operator and completed the proof like the proof of the Banach's fixed point theorem.

On the other hand, the PIM was utilized for solving various kind of differential equations like Abel equation [8], nonlinear chaotic Genesio system [9], boundary value problems [10], linear optimal control problems [11] and etc. Convergence theorem for some particular cases was discussed in some of these literature (e.g. [8,9]), but what is still missing is a proof of the convergence of the PIM for a general differential equation. Also, from the both theoretical and practical viewpoint, another necessary talk is a complete discussion about the error bound of the approximations. Therefore, the goal of this article is to establish an error term and then presenting a general proof of the convergence of the PIM.

\section{Parametric iteration method (PIM)}

To explain the basic idea of the PIM considers the following differential equation:

$\mathcal{A}[\mathrm{x}(\mathrm{t})]=0, \mathrm{x}\left(\mathrm{t}_{0}\right)=\mathrm{x}_{0}$.

Where $\mathcal{A}$ is a nonlinear operator, $\mathrm{t}$ denotes the time, and $\mathrm{x}(\mathrm{t})$ is an unknown variable. First consider (1) as below:

$\mathcal{L}[\mathrm{x}(\mathrm{t})]+\mathcal{N}[\mathrm{x}(\mathrm{t})]=\mathrm{g}(\mathrm{t}), \mathrm{t}>\mathrm{t}_{0}$. 
Where $\mathcal{L}$ and $\mathcal{N}$ denote linear and nonlinear differential operator of the unknown $\mathrm{x}(\mathrm{t})$ respectively, and $\mathrm{g}(\mathrm{t})$ is the source term. We then construct a family of iterative formulas as:

$\mathcal{L}\left[\mathrm{x}_{\mathrm{n}+1}(\mathrm{t})-\mathrm{x}_{\mathrm{n}}(\mathrm{t})\right]=\mathrm{hH}(\mathrm{t}) \mathcal{A}\left[\mathrm{x}_{\mathrm{n}}(\mathrm{t})\right]$

where $x_{n+1}\left(t_{0}\right)=x_{n}\left(t_{0}\right), n=0,1,2, \ldots$. In this formula $h \neq 0$ and $H(t) \neq 0$ denote the so-called auxiliary parameter and auxiliary function respectively. In this work we take $H(t)=1$. Accordingly, the successive approximations $x_{n}(t), n \geq 1$ will be readily obtained by choosing the zeroth component $x_{0}(t)$. (For more details about PIM see [1]).

\section{Error analysis and convergence}

Consider the following nonlinear problem

$\dot{X}=F(X(t), t), X\left(t_{0}\right)=X_{0}$,

Where $X:\left[\mathrm{t}_{0}, \mathrm{t}_{\mathrm{f}}\right] \rightarrow \mathbb{R}^{\mathrm{k}}$ and $\mathrm{F}: \mathbb{R}^{\mathrm{k}} \times\left[\mathrm{t}_{0}, \mathrm{t}_{\mathrm{f}}\right] \rightarrow \mathbb{R}^{\mathrm{k}}$ are defined as:

$X(t)=\left(\begin{array}{c}x_{1}(t) \\ x_{2}(t) \\ \vdots \\ x_{k}(t)\end{array}\right), F(X(t), t)=\left(\begin{array}{c}f_{1}\left(x_{1}(t), x_{2}(t), \ldots, x_{k}(t), t\right) \\ f_{2}\left(x_{1}(t), x_{2}(t), \ldots, x_{k}(t), t\right) \\ \vdots \\ f_{k}\left(x_{1}(t), x_{2}(t), \ldots, x_{k}(t), t\right)\end{array}\right)$,

Where $x_{i}(t) \in C\left[t_{0}, t_{f}\right]$ and $f_{i}(X(t), t)$ are continuous real functions on $\mathbb{R}^{k} \times\left[t_{0}, t_{f}\right]$. In $\mathbb{R}^{k}$ we use the infinity norm i.e. for vector $y=\left(y_{1}, y_{2}, \ldots, y_{k}\right)^{T} \in \mathbb{R}^{k}$ we have $\|y\|=\max _{i}\left|y_{i}\right|, i=1,2, \ldots, k$ and for every $x(t) \in C\left[t_{0}, t_{f}\right]$, we use the maximum norm as $\|\mathrm{x}\|=\max |\mathrm{x}(\mathrm{t})|_{\mathrm{t} \in\left[\mathrm{t}_{0}, \mathrm{t}_{\mathrm{f}}\right]}$. Also the norm of vector functions like $\mathrm{X}(\mathrm{t})$ is:

$\|\mathrm{X}\|=\max _{\mathrm{i}}\left\{\max _{\mathrm{t} \in\left[\mathrm{t}_{0}, \mathrm{t}_{\mathrm{f}}\right]}\left|\mathrm{x}_{\mathrm{i}}(\mathrm{t})\right|\right\}, \mathrm{i}=1,2, \ldots, \mathrm{k}$

In order to use the PIM, we rewrite (4) as

$\mathcal{L}[\mathrm{X}(\mathrm{t})]+\mathcal{N}[\mathrm{X}(\mathrm{t})]=0$,

Where $\mathcal{L}[\mathrm{X}]=\dot{\mathrm{X}}$ is an auxiliary linear operator and $\mathcal{N}[\mathrm{X}(\mathrm{t})]=-\mathrm{F}(\mathrm{X}(\mathrm{t}), \mathrm{t})$ is the nonlinear operator. Then the constructed iteration formula by PIM will be defined by:

$\mathrm{X}_{\mathrm{n}+1}(\mathrm{t})=\mathrm{X}_{\mathrm{n}}(\mathrm{t})+\mathrm{h} \int_{\mathrm{t}_{0}}^{\mathrm{t}} \mathrm{H}(\mathrm{s})\left[\dot{X}_{\mathrm{n}}(\mathrm{s})-\mathrm{F}\left(\mathrm{X}_{\mathrm{n}}(\mathrm{s}), \mathrm{s}\right)\right] \mathrm{ds}, \mathrm{n}=0,1, \ldots$

Taking $\mathrm{H}(\mathrm{t})=1$ and choosing the initial approximation $\mathrm{X}_{0}(\mathrm{t})=\mathrm{X}\left(\mathrm{t}_{0}\right)$ in the above sequence, clearly we can say that $\mathrm{X}_{\mathrm{n}}\left(\mathrm{t}_{0}\right)=\mathrm{X}_{\mathrm{n}-1}\left(\mathrm{t}_{0}\right)=\cdots=\mathrm{X}_{0}\left(\mathrm{t}_{0}\right)=\mathrm{X}\left(\mathrm{t}_{0}\right)=\mathrm{X}_{0}$. So the following lemma will be obtained.

Lemma 3.1: For every $n \in \mathbb{N} \cup\{0\}$ and for every $t>t_{0}$

$\int_{\mathrm{t}_{0}}^{\mathrm{t}} \dot{\mathrm{X}}_{\mathrm{n}}(\mathrm{s}) \mathrm{ds}=\mathrm{X}_{\mathrm{n}}(\mathrm{t})-\mathrm{X}_{\mathrm{n}}\left(\mathrm{t}_{0}\right)=\mathrm{X}_{\mathrm{n}}(\mathrm{t})-\mathrm{X}_{0}$.

Now the iteration formula (8) can be written as

$X_{n+1}(t)=(1+h) X_{n}(t)-h X_{0}-h \int_{t_{0}}^{t} F\left(X_{n}(s), s\right) d s, n=0,1, \ldots$

Let's denote $n^{\text {th }}$ approximation by $X_{n}(t)=\left(x_{1}{ }^{n}(t), x_{2}{ }^{n}(t), \ldots, x_{k}{ }^{n}(t)\right)^{T} \in \mathbb{R}^{k}$ and $X(t)=\left(x_{1}(t), x_{2}(t), \ldots, x_{k}(t)\right)^{T} \in \mathbb{R}^{k}$ then the convergence of $X_{n}(t)$ is due to the norm

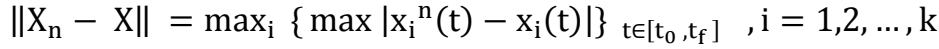

Before presenting the main theorem, we restate the Lipschitz condition for the vector function $F(X(t)$, $t)$. Suppose that for every the component $f_{i}(X(t), t), i=1, \ldots, k$ of function $F(X(t), t)$, there exist a positive real constant $L_{i}$ such that for every $t \in\left[\mathrm{t}_{0}, \mathrm{t}_{\mathrm{f}}\right]$ and for every $\mathrm{X}(\mathrm{t})=\left(\mathrm{x}_{1}(\mathrm{t}), \mathrm{x}_{2}(\mathrm{t}), \ldots, \mathrm{x}_{\mathrm{k}}(\mathrm{t})\right)^{\mathrm{T}} \in \mathbb{R}^{\mathrm{k}}$ and $\mathrm{Y}(\mathrm{t})=\left(\mathrm{y}_{1}(\mathrm{t}), \mathrm{y}_{2}(\mathrm{t}), \ldots, \mathrm{y}_{\mathrm{k}}(\mathrm{t})\right)^{\mathrm{T}} \in \mathbb{R}^{\mathrm{k}}$ the following condition satisfies:

$\left|f_{i}\left(x_{1}, x_{2}, \ldots, x_{k}, t\right)-f_{i}\left(y_{1}, y_{2}, \ldots, y_{k}, t\right)\right| \leq L_{i}\left(\left|x_{1}(t)-y_{1}(t)\right|+\cdots+\left|x_{k}(t)-y_{k}(t)\right|\right)$

In this situation, letting $\mathrm{L}=\mathrm{k} \times \max _{\mathrm{i}=1, \ldots, \mathrm{k}}\left\{\mathrm{L}_{\mathrm{i}}\right\}$ we can say that $\mathrm{F}(\mathrm{X}(\mathrm{t}), \mathrm{t})$ satisfies a Lipschitz condition with respect to the first argument with the Lipschitz constant L, i.e.

$\|\mathrm{F}(\mathrm{X})-\mathrm{F}(\mathrm{Y})\| \leq \mathrm{L}\|\mathrm{X}-\mathrm{Y}\|$.

Theorem 3.2: Assume that $F(X(t), t)$ is continuous on $E=\mathbb{R}^{k} \times I$ where $I=\left[t_{0}, t_{f}\right]$ and satisfies a Lipschitz condition on $E$ with respect to the first argument with the Lipschitz constant $L$. Also suppose that $F\left(X_{0}(t), t\right)$ is bounded on $E$ to a positive real number $\mathrm{M}$. Then for two arbitrary successive approximations we have

$\left\|X_{n+1}-X_{n}\right\| \leq \frac{M}{L} \sum_{j=0}^{n}\left(\begin{array}{c}n \\ j\end{array}\right)|1+h|^{n-j} \frac{\left[L \cdot|h| \cdot\left|t_{f}-t_{0}\right|\right]^{j+1}}{(j+1) !}$.

Proof: If we denote the approximate solution obtained by the first iteration with $\mathrm{X}_{1}(\mathrm{t})=\left(\mathrm{x}_{1}{ }^{1}(\mathrm{t}), \mathrm{x}_{2}{ }^{1}(\mathrm{t}), \ldots, \mathrm{x}_{\mathrm{k}}{ }^{1}(\mathrm{t})\right)^{\mathrm{T}}$ and $\mathrm{X}_{0}(\mathrm{t})=\left(\mathrm{x}_{1}{ }^{0}(\mathrm{t}), \mathrm{x}_{2}{ }^{0}(\mathrm{t}), \ldots, \mathrm{x}_{\mathrm{k}}{ }^{0}(\mathrm{t})\right)^{\mathrm{T}}$, according to (10) and noticing that $\left|\mathrm{f}_{\mathrm{i}}\left(\mathrm{X}_{0}(\mathrm{~s}), \mathrm{s}\right)\right| \leq\left\|\mathrm{F}\left(\mathrm{X}_{0}\right)\right\| \leq \mathrm{M}$ where $\mathrm{t}_{0} \leq$ $\mathrm{s} \leq \mathrm{t} \leq \mathrm{t}_{\mathrm{f}}$ and $\mathrm{i}=1, \ldots, \mathrm{k}$ we can write

$\left|\mathrm{x}_{\mathrm{i}}{ }^{1}(\mathrm{t})-\mathrm{x}_{\mathrm{i}}{ }^{0}(\mathrm{t})\right| \leq|\mathrm{h}| \int_{\mathrm{t}_{0}}^{\mathrm{t}}\left|\mathrm{f}_{\mathrm{i}}\left(\mathrm{X}_{0}(\mathrm{~s}), \mathrm{s}\right)\right| \mathrm{ds} \leq|\mathrm{h}| \mathrm{M}\left|\mathrm{t}-\mathrm{t}_{0}\right|, \mathrm{i}=1, \ldots, \mathrm{k}, \forall \mathrm{t} \in \mathrm{I}$.

Now, let $\mathrm{n}=1$ in (10), using the notation $\mathrm{X}_{2}(\mathrm{t})=\left(\mathrm{x}_{1}{ }^{2}(\mathrm{t}), \mathrm{x}_{2}{ }^{2}(\mathrm{t}), \ldots, \mathrm{x}_{\mathrm{k}}{ }^{2}(\mathrm{t})\right)^{\mathrm{T}}$, we have

$$
\begin{aligned}
\left|x_{i}{ }^{2}(t)-x_{i}{ }^{1}(t)\right| & \leq|1+h|\left|x_{i}{ }^{1}(t)-x_{i}{ }^{0}(t)\right|+|h| \int_{t_{0}}^{t}\left|f_{i}\left(X_{1}(s), s\right)-f_{i}\left(X_{0}(s), s\right)\right| d s \\
& \leq|1+h||h| M\left|t-t_{0}\right|+|h| \int_{t_{0}}^{t} L_{i}\left(\left|x_{1}{ }^{1}(s)-x_{1}{ }^{0}(s)\right|+\cdots+\left|x_{k}{ }^{1}(s)-x_{k}{ }^{0}(s)\right|\right) d s \\
& \leq|1+h||h| M\left|t-t_{0}\right|+|h| L_{i} \int_{t_{0}}^{t}\left(k \times|h| M\left|s-t_{0}\right|\right) d s
\end{aligned}
$$




$$
\begin{aligned}
& \leq|1+h||h| M\left|t-t_{0}\right|+|h|^{2} L M \frac{\left|t-t_{0}\right|^{2}}{2} \\
& =\frac{M}{L}\left(|1+h|\left[L .|h| .\left|t-t_{0}\right|\right]+\frac{\left[L .|h| \cdot\left|t-t_{0}\right|\right]^{2}}{2}\right), \quad i=1, \ldots, k, \quad \forall t \in I .
\end{aligned}
$$

We rearrange the final statement as bellow

$\left|\mathrm{x}_{\mathrm{i}}{ }^{2}(\mathrm{t})-\mathrm{x}_{\mathrm{i}}{ }^{1}(\mathrm{t})\right|=\frac{\mathrm{M}}{\mathrm{L}} \sum_{\mathrm{j}=0}^{1}\left(\begin{array}{l}1 \\ \mathrm{j}\end{array}\right)|1+\mathrm{h}|^{1-\mathrm{j}} \frac{\left[\mathrm{L} \cdot \mathrm{|}|\mathrm{|}| \cdot \mathrm{t}-\mathrm{t}_{\mathrm{o}} \mid\right]^{\mathrm{j}+1}}{(\mathrm{j}+1) !}, \mathrm{i}=1, \ldots, \mathrm{k}, \forall \mathrm{t} \in \mathrm{I}$.

And similarly

$\left|\mathrm{x}_{\mathrm{i}}{ }^{3}(\mathrm{t})-\mathrm{x}_{\mathrm{i}}{ }^{2}(\mathrm{t})\right| \leq \frac{\mathrm{M}}{\mathrm{L}} \sum_{\mathrm{j}=0}^{2}\left(\begin{array}{l}2 \\ \mathrm{j}\end{array}\right)|1+\mathrm{h}|^{2-\mathrm{j}} \frac{\left[\mathrm{L} \cdot|\mathrm{h}| \cdot\left|\mathrm{t}-\mathrm{t}_{0}\right|\right]^{\mathrm{j}+1}}{(\mathrm{j}+1) !}, \mathrm{i}=1, \ldots, \mathrm{k}, \forall \mathrm{t} \in \mathrm{I}$.

In summary, this argument will lead to the following general form

$\left.\mid \mathrm{x}_{\mathrm{i}}{ }^{\mathrm{n}+1}(\mathrm{t})-\mathrm{x}_{\mathrm{i}}{ }^{\mathrm{n}} \mathrm{t}\right)\left|\leq \frac{\mathrm{M}}{\mathrm{L}} \sum_{\mathrm{j}=0}^{\mathrm{n}}\left(\begin{array}{l}\mathrm{n} \\ \mathrm{j}\end{array}\right)\right| 1+\left.\mathrm{h}\right|^{\mathrm{n}-\mathrm{j}} \frac{\left[\mathrm{L} \cdot|\mathrm{h}| \cdot\left|\mathrm{t}-\mathrm{t}_{0}\right|\right]^{\mathrm{j}+1}}{(\mathrm{j}+1) !}, \mathrm{i}=1, \ldots, \mathrm{k}, \forall \mathrm{t} \in \mathrm{I}$.

The maximum of left hand side on index $i$ satisfies (18) too, due to the fact that the right hand side of (18) is independent from index $i$. So, due to the defined norm (6), taking maximum of both side of (18) on all $t \in\left[t_{0}, t_{f}\right]$, we have:

$\left\|X_{n+1}-X_{n}\right\| \leq \frac{M}{L} \sum_{j=0}^{n}\left(\begin{array}{c}n \\ j\end{array}\right)|1+h|^{n-j} \frac{\left[L \cdot|h| \cdot\left|t_{f}-t_{0}\right|\right]^{j+1}}{(j+1) !}$.

This completes the proof.

Now we want to prove that if we choose $h$ such that $|1+h|<1$, then the right hand side of (14) vanishes when $n$ tends to infinity. First we prove an auxiliary lemma.

Lemma 3.3: Assume that $|1+h|<1$, then for every $j \in \mathbb{N} \cup\{0\}$ where $j \leq n$ we have

$\lim _{n \rightarrow \infty}\left(\begin{array}{l}n \\ j\end{array}\right)|1+h|^{n-j}=0$.

Proof: For a fixed $\mathrm{j} \leq \mathrm{n}$ we have $\left(\begin{array}{l}\mathrm{n} \\ j\end{array}\right) \leq \mathrm{n}^{\mathrm{j}}$. So

$0<\lim _{n \rightarrow \infty}\left(\begin{array}{l}n \\ j\end{array}\right)|1+h|^{n-j} \leq \lim _{n \rightarrow \infty} \frac{n^{j}}{\left|\frac{1}{1+h}\right|^{n-j}}$

Also for every real number $j$ and $t>1$ we know that $\lim _{n \rightarrow \infty} \frac{n^{j}}{t^{n}}=0$. Therefore noticing to the assumption $|1+h|<1$ and taking $\mathrm{t}=\left|\frac{1}{1+\mathrm{h}}\right|>1$ will complete the proof.

Theorem 3.4: Due to the last assumption we have

$\lim _{n \rightarrow \infty} \sum_{j=0}^{n}\left(\begin{array}{l}n \\ j\end{array}\right)|1+h|^{n-j} \frac{\left(L \cdot|h| \cdot\left|t_{-}-t_{0}\right|\right)^{j+1}}{(j+1) !}=0$.

Proof: Let $b_{j+1}=\frac{\left(L \cdot|h| \cdot\left|t_{f}-t_{0}\right|\right)^{j+1}}{(j+1) !}$ and $a_{n-j}=\left(\begin{array}{l}n \\ j\end{array}\right)|1+h|^{n-j}$. Therefore the sum in (22) can be written as

$\gamma_{n}=\sum_{j=0}^{n} a_{n-j} b_{j+1}$

Or

$\gamma_{n}=a_{0} b_{n+1}+a_{1} b_{n}+\cdots+a_{n} b_{1}$.

Noticing to the expansion of the exponential function and $\frac{\left(\mathrm{L} \cdot|\mathrm{h}| \cdot\left|\mathrm{t}_{\mathrm{f}}-\mathrm{t}_{0}\right|\right)^{j+1}}{(\mathrm{j}+1) !}>0$ for all $\mathrm{j}$, the series $\sum_{j=0}^{\infty} b_{j+1}$ is absolutely convergent and we name its sum $\beta$. Clearly, the limit of $b_{n}$ is zero. Also, by lemma 3.3 we know that $a_{n} \rightarrow 0$. So, for every given $\varepsilon>0$ there exist a $N>0$ such that for every $n \geq N$ we have $\left|a_{n}\right|<\varepsilon$. In this case we can write

$$
\begin{aligned}
\left|\gamma_{n}\right| & \leq\left|a_{0} b_{n+1}+\cdots+a_{N} b_{n-N+1}\right|+\left|a_{N+1} b_{n-N}+\cdots+a_{n} b_{1}\right| \\
& \leq\left|a_{0} b_{n+1}+\cdots+a_{N} b_{n-N+1}\right|+\varepsilon\left(\left|b_{1}\right|+\left|b_{2}\right|+\cdots+\left|b_{n-N}\right|\right) \\
& \leq\left|a_{0} b_{n+1}+\cdots+a_{N} b_{n-N+1}\right|+\varepsilon \beta
\end{aligned}
$$

In the last inequality absolutely convergence of $\sum_{j=0}^{\infty} b_{j+1}$ is used. On the other hand, as $n$ tends to infinity $b_{n} \rightarrow 0$. So if we keep $\mathrm{N}$ fixed and let $\mathrm{n} \rightarrow \infty$ then we have

$\lim _{n \rightarrow \infty} \sup \left|\gamma_{\mathrm{n}}\right| \leq \varepsilon \beta$

Since the $\varepsilon>0$ was arbitrary, the proof is complete.

Theorem 3.2 and 3.4 indicate that for sufficiently large $n$, two successive terms of the sequence $X_{n}(t)$ for every arbitrary $\varepsilon>0$ satisfy the following relation

$\left\|\mathrm{X}_{\mathrm{n}+1}-\mathrm{X}_{\mathrm{n}}\right\|<\varepsilon$

Using this, one can easily show that $X_{n}(t)$ is a Cauchy sequence in $\mathbb{R}^{k}$. Therefor it is convergent in the complete space $\mathbb{R}^{\mathrm{k}}$. So we have:

Corollary 3.5: Due to the last assumptions, the sequence (10) constructed by the PIM is convergent.

Corollary 3.6: The valid region of the convergence-control parameter $\mathrm{h}$ is $-2<h<0$.

\section{Numerical experiments}

To demonstrate the efficiency of the error bound defined by (14) we consider the following two dimensional test problems. 
$\{\dot{\mathrm{x}}=\mathrm{x}(\mathrm{t})+\mathrm{u}(\mathrm{t}), \quad \mathrm{x}(0)=1$,

$\{\dot{\mathrm{u}}=\mathrm{x}(\mathrm{t})-\mathrm{u}(\mathrm{t}), \quad \mathrm{u}(0)=-1.69$

Where the time domain is $\left[\mathrm{t}_{0}, \mathrm{t}_{\mathrm{f}}\right]=[0,1]$ and the exact solutions from [12] are:

$x(t)=\frac{e^{\sqrt{2} t}}{(3-2 \sqrt{2}) e^{2 \sqrt{2}}+1}+\frac{e^{-\sqrt{2} t}}{(3+2 \sqrt{2}) e^{-2 \sqrt{2}}+1}$,

$u(t)=\frac{(\sqrt{2}-1) e^{\sqrt{2} t}}{(3-2 \sqrt{2}) e^{2 \sqrt{2}}+1}-\frac{(\sqrt{2}+1) e^{-\sqrt{2}} t}{(3+2 \sqrt{2}) e^{-2 \sqrt{2}}+1}$.

In view of (4) and (5) we have:

$X(t)=\left(\begin{array}{l}x(t) \\ u(t)\end{array}\right), F(X(t), t)=A X(t), A=\left(\begin{array}{cc}1 & 1 \\ 1 & -1\end{array}\right), X(0)=\left(\begin{array}{c}1 \\ -1.69\end{array}\right)$.

$\mathrm{F}(\mathrm{X}(\mathrm{t}), \mathrm{t})$ is linear and obviously, it satisfies a Lipschitz condition by Lipschitz constant $\mathrm{L}=\|\mathrm{A}\|_{\infty}=2$. Choosing $\mathrm{X}_{0}(\mathrm{t})=\mathrm{X}(0)$, the $\mathrm{F}\left(\mathrm{X}_{0}(\mathrm{t}), \mathrm{t}\right)$ is bounded by $\mathrm{M}=2.69$ and using the notation $\mathrm{E}_{\text {bound }}$ for the error bound described in (14) we have:

$\mathrm{E}_{\text {bound }}=\frac{2.69}{2} \sum_{\mathrm{j}=0}^{\mathrm{n}}\left(\begin{array}{l}\mathrm{n} \\ \mathrm{j}\end{array}\right)|1+\mathrm{h}|^{\mathrm{n}-\mathrm{j}} \frac{(2|\mathrm{~h}|)^{\mathrm{j}+1}}{(\mathrm{j}+1) !}$.

Furthermore the norm of direct difference of two successive approximations $X_{n+1}(t)$ and $X_{n}(t)$ appeared in the left hand side of (14) is denoted by

$\mathrm{E}_{\text {direct }}=\left\|\mathrm{X}_{\mathrm{n}+1}-\mathrm{X}_{\mathrm{n}}\right\|$.

Then for every $n=0,1,2, \ldots$ and for all $t \in[0,1]$ the numerical results must confirm the relation $E_{\text {direct }} \leq E_{\text {bound }}$ to ensure that the theoretical result of the Theorem 3.2 is reliable.

Also in order to discuss the convergence of the PIM claimed in the Corollary 3.5, we denote the absolute error by

$\mathrm{E}_{\text {absolute }}$ and define it by

$\mathrm{E}_{\text {absolute }}=\left\|\mathrm{X}_{\text {exact }}-\mathrm{X}_{\mathrm{n}}\right\|$.

In Fig.1, we plot $E_{\text {direct }}, E_{\text {bound }}$ and $E_{\text {absolute }}$ obtained by the PIM with $\mathrm{n}=20$ and $\mathrm{h}=-1.25$. Other different values of $\mathrm{h}$ and $\mathrm{n}$ is discussed in Fig.2 and Table 1.

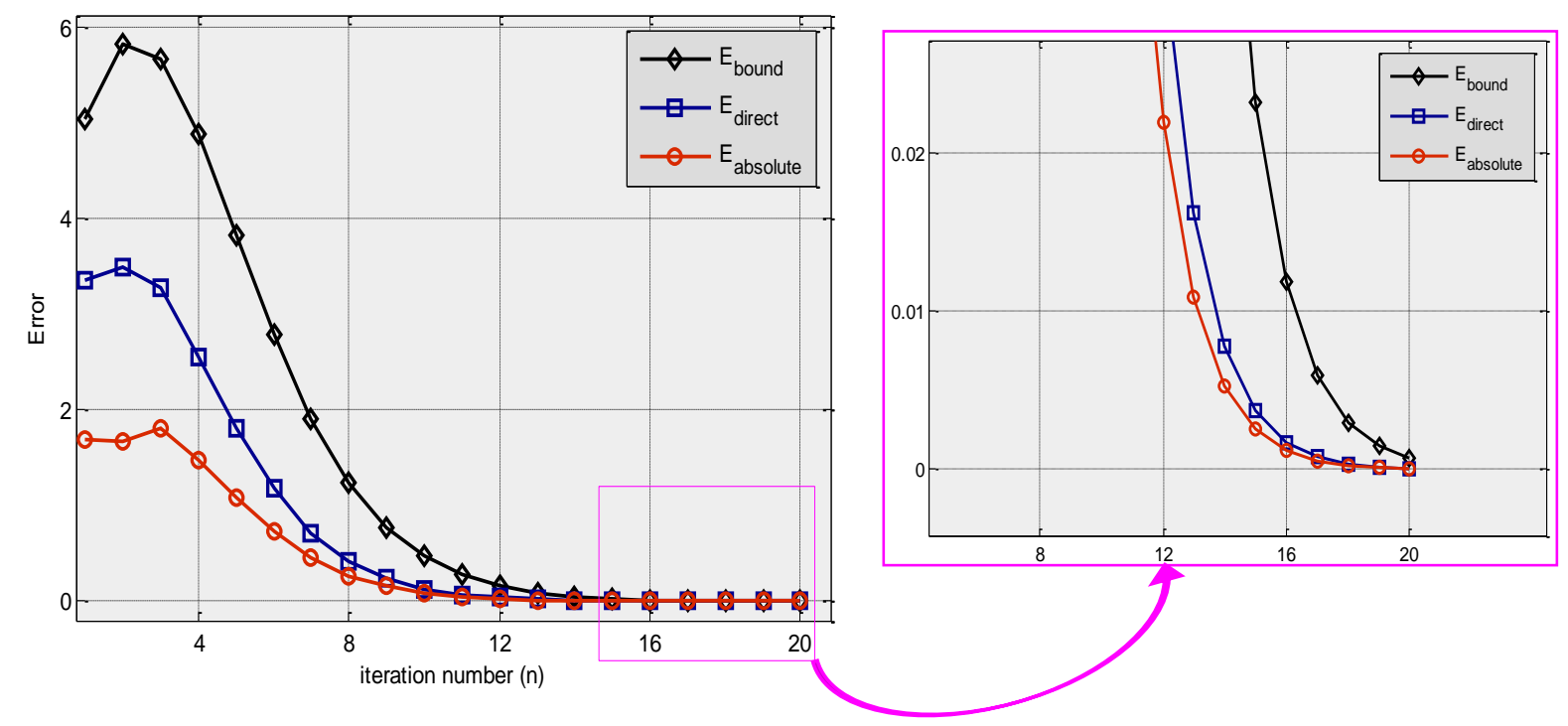

Fig. 1: Plot of Error Due To the Iteration Number ( $n=20$ and $h=-1.25$ )

\section{Analysis of the Fig.1:}

Error bound: As could be seen from the plot of $E_{\text {bound }}$, the estimated error bound is really an upper bound for $\left\|X_{n+1}-X_{n}\right\|$ which confirms the inequality (14). This is true for every iteration as zoomed out part shows. Plot of $\mathrm{E}_{\text {bound }}$ also shows that by increasing $\mathrm{n}$ the error bound vanishes which is a confirmation of theorem 3.4.

Cauchy sequence: The plot of $E_{\text {direct }}$ shows that $E_{\text {direct }} \rightarrow 0$ when $n$ grows. This means that for every $\varepsilon>0$ and for sufficiently large $n,\left\|X_{n+1}-X_{n}\right\|<\varepsilon$ which confirms (27). The latter can be used to conclude the sequence $X_{n}(t)$ is a Cauchy sequence.

Convergence: The plot of $E_{\text {absolute }}$ shows that for sufficiently large $n,\left\|X_{\text {exact }}-X_{n}\right\| \rightarrow 0$, and this is a confirmation of convergence of the sequence $X_{n}(t)$ constructed by the PIM. 

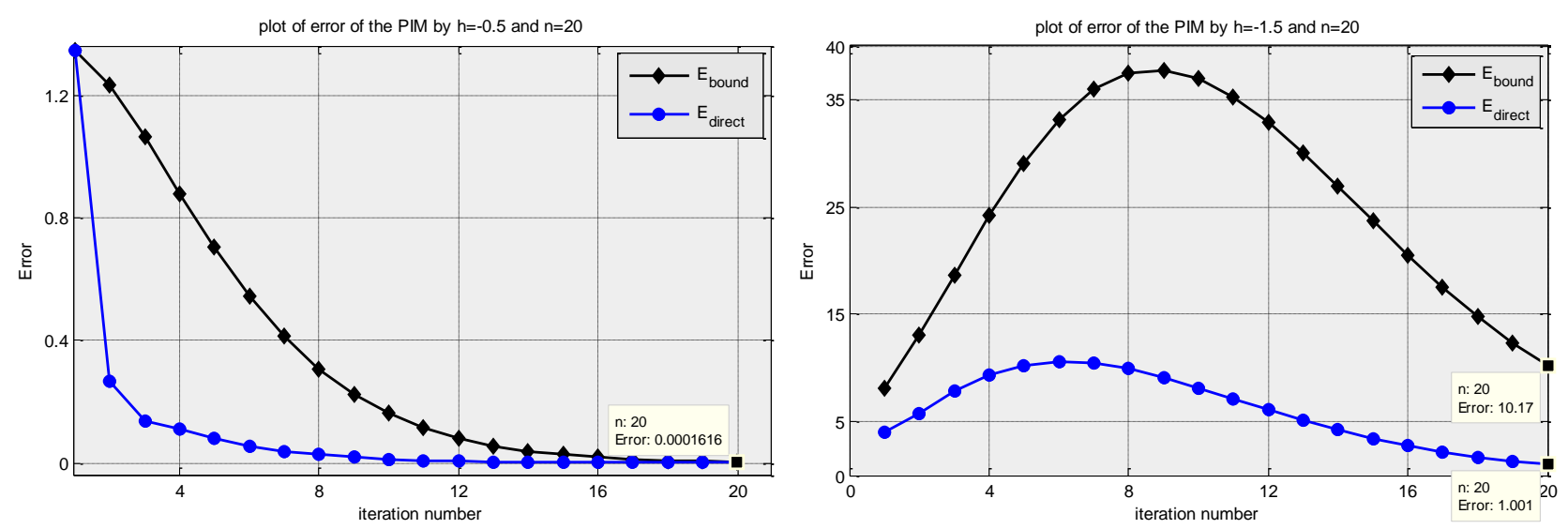

Fig. 2: Test of Error Bound. Left: $n=20$ and $h=-0.5$; Right: $n=20$ and $h=-1.5$

In Fig.2, we plot $E_{\text {direct }}$ and $E_{\text {bound }}$ for the solutions of the PIM by various $h$ and $n$. As could be seen the error bound confirms what is claimed in theorem 3.2 and 3.4.

Although Fig.1 and Fig.2 provide us good information of error bound, but what is doesn't show is a specified data for the convergence rate. So to study of the convergence rate we report the final values of $E_{\text {direct }}$ and $E_{b o u n d}$ for $n=20$ and $\mathrm{n}=40$ in Table 1 .

Table 1: Test of Error Bound for Various $h$ And $n$

\begin{tabular}{|c|cc|cc|}
\hline$n$ & \multicolumn{2}{|c|}{$n=20$} & \multicolumn{2}{c|}{$n=40$} \\
\hline$h$ & $E_{\text {direct }}$ & $E_{\text {bound }}$ & $E_{\text {direct }}$ & $E_{\text {bound }}$ \\
\hline$h=-0.5$ & 0.0001 & 0.003 & $10^{-9}$ & $10^{-7}$ \\
$h=-1.0$ & $10^{-16}$ & $10^{-14}$ & $10^{-42}$ & $10^{-37}$ \\
$h=-1.5$ & 1.001 & 10.169 & 0.001 & 0.041 \\
\hline
\end{tabular}

Table 1 shows that for $\mathrm{h}=-1$ the convergence is excellent but for $\mathrm{h}=-1.5$ we need much more iterations to conclude the convergence. For $h=-1.5$, although $|1+h|=0.5$ seems to be appropriate for vanishing $|1+h|^{n-j}$ but bigness of $|\mathrm{h}|$ in the same formula (32) makes $(2 .|\mathrm{h}|)^{\mathrm{j}+1}$ very big. On the other hand, for $\mathrm{h}=-0.5$, similarly $|1+\mathrm{h}|=0.5 \mathrm{but}$ $|\mathrm{h}|$ is not very big in opposite of the case $\mathrm{h}=-1.5$, consequently the convergence is faster. From this viewpoint, $\mathrm{h}=-1$ seems to be the best choice since $|1+\mathrm{h}|=0$, however there exist many counterexamples in nonlinear problems showing that some values other than -1 can give better approximations. Such an argument leads to a known problem that is finding an optimal value of accelerating parameter $\mathrm{h}$ which in general is an open problem in this field. By the results of this paper a proposal is minimizing the error term as a function of the parameter $h$ as a variable which is left to the further works.

\section{Conclusion}

In this paper, a convergence analysis of the PIM is presented. This is performed by establishing a novel error bound and showing this error bound tends to zero. Also an interesting result has been concluded for the auxiliary parameter $h$. Although finding optimal $\mathrm{h}$ in general is an open problem, but we hope that the results of this paper are a promising tools for researchers. Our proposal is to find optimal h by minimizing the presented error term as a function of $h$, which is left to the further works.

\section{References}

[1] A. Ghorbani, "Toward a New Analytical Method for Solving Nonlinear Fractional Differential Equations", Comput. Meth. Appl. Mech. Engrg. Vol.197, (2008), pp: 4173-4179. http://dx.doi.org/10.1016/j.cma.2008.04.015.

[2] J. H. He, "Variational iteration method - a kind of non-linear analytical technique: some examples", Int. J. Non-Linear Mech. Vol.34, (1999), pp: 699-708. http://dx.doi.org/10.1016/S0020-7462(98)00048-1.

[3] S. Yang, A. Xiao, H. Sua, "Convergence of the variational iteration method for solving multi-order fractional differential equations", Computers and Mathematics with Applications, Vol.60, (2010), pp: 2871-2879. http://dx.doi.org/10.1016/j.camwa.2010.09.044.

[4] S. Yang, A. Xiao, "convergence of variational iteration method for solving multi-delay differential equations", computers \& mathematics with applications, Vol.61, No.8, (2011), pp: 2148-2151.

[5] E. Yusufoğlu, "Two convergence theorems of variational iteration method for ordinary differential equations", Appl. Math. Lett. (2011), http://dx.doi.org/10.1016/j.aml.2011.02.005.

[6] D. Khojasteh,"convergence of variational iteration method for solving linear systems of ODE's with constant coefficients", computers \& mathematics with applications, Vol.56, No.8,(2008),pp: 2027-2033. 
[7] Z. M. Odibat, "A study on the convergence of variational iteration method," Mathematical and Computer Modelling Vol.51, (2010), pp: 1181_1192.

[8] J. Saberi-Nadjafi, A. Ghorbani, "Piecewise-truncated parametric iteration method: a promising analytical method for solving Abel differential equations", Z. Naturforsch. Vol.65a, (2010), pp: 529-539.

[9] A. Ghorbani and J. Saberi-Nadjafi, "A Piecewise-Spectral Parametric Iteration Method for Solving the Nonlinear Chaotic Genesio System", Mathematical and Computer Modeling, Vol.54, (2011), pp: 131-139. http://dx.doi.org/10.1016/j.mcm.2011.01.044.

[10] A. Ghorbani, M. Gachpazan, J. Saberi-Nadjafi, "A modified parametric iteration method for solving nonlinear second order BVPs", Comput. Appl. Math. Vol.30, No.3, (2011), pp: 499-515. http://dx.doi.org/10.1590/S1807-03022011000300002.

[11] A. S. Alavi, A. Heydari, "Parametric Iteration Method for Solving Linear Optimal Control Problems", Applied Mathematics, Vol.3, (2012), pp 1059-1064. http://dx.doi.org/10.4236/am.2012.39155.

[12] C. K. Chui and G. Chen, "Linear Systems and Optimal Control", Springer-Verlag, Berlin, Heidelberg, (1989), pp:76-80 http://dx.doi.org/10.1007/978-3-642-61312-8. 